\title{
Synthesis and Application of Locust Bean Gum Grafted Polyaniline in Removal of Methyl Orange Dye
}

\author{
E. Fosso-Kankeu, L. van der Merwe, S. Pandey, F. Waanders and S.K. Ntwampe
}

\begin{abstract}
Nowadays, the use of natural and modified polymers for the removal of dyes from wastewater is becoming more common. We briefly summarize some of the results in this article. The present study focuses mainly on the synthesis of locust bean gum grafted polyaniline (LGP) via in situ oxidative polymerization using ammonium persulfate (APS) as an oxidant in an acidic medium. The LGP adsorbent was characterized by using Fourier Transfer Infrared spectroscopy (FT-IR). The adsorption efficiency and the adsorption capacity of the prepared adsorbent was evaluated by observing the adsorption of methyl orange (MO) as an anionic dye from aqueous solutions. Batch-sorption experiments were carried out to evaluate the influence of adsorbent dose on the adsorption of MO dye. It can be observed the optimized condition of 120 minutes, a dosage of $1.6 \mathrm{~g} / \mathrm{L}$ LGP adsorbent showed the best results for the adsorption capacity $(\mathrm{mg} / \mathrm{g})$ and dye removal efficiency (\%) of 20.58, and 66, respectively.

Index Terms-Biopolymer; Polyaniline; locust bean gum, methyl orange, Adsorption
\end{abstract}

\section{INTRODUCTION}

Industrial activities like the manufacturing of leather, plastic, paper, and the processing of food produce wastewater that contains organic pollutants that have several environmental concerns [1-3]. When an organic dye of synthetic origin is dispersed in water, it can be classified as one of these pollutants since it decreases the quality of the water, making it difficult to treat due to its synthetic origin and complex molecular structure which makes it non-biodegradable [4]. These non-biodegradable dyes can cause the formation of cancer and genetic mutations in humans [1], as well as decrease the photosynthetic activity of aquatic organisms [5]. Dyes can be classified based on their particle charge after they have been dissolved in an aquatic medium. The classes include cationic, anionic, and non-ionic [6]. Methyl orange (MO) is classified as an anionic dye [2].

Manuscript received September 9, 2020. This work was supported by Prof Elvis Fosso-Kankeu Research Incentive fund.

E. Fosso-Kankeu, L. van der Merwe, F. Waanders and S.K. Ntwampe are with the Water Pollution Monitoring and Remediation Initiatives Research Group in the School of Chemical and Minerals Engineering, North-West University, Potchefstroom, South Africa.

S. Pandey is with the Particulate Matter Research Center, Research Institute of Industrial Science \& Technology (RIST), 187-12, Geumho-ro, Gwangyang-si, Jeollanam-do 57801, South Korea.
There are a lot of techniques available to remove organic dyes from aqueous solutions. Some of these techniques include filtration, coagulation-flocculation, photo- and catalytic degradation, oxidation, biological treatment, and adsorption [1,7-13]. Among these, adsorption is probably the most environmentally friendly technique available to remove organic dyes from aqueous solutions as it has the benefit of completely removing the dye molecule as compared to other techniques that leave behind harmful portions of the dye $[14,15]$. Furthermore, the adsorption method has advantages like its simple design, effectiveness, efficiency, easy operation, economic viability, and the fact that it is insensitive to toxic pollutants $[1,6,16]$. In recent years, the demand for low-cost, highly effective, and environmentally friendly adsorbents have increased substantially $[1,5,7]$.

Polyaniline (PANI) is a conducting polymer and is used in a variety of applications like antistatic and anticorrosion coating, batteries, and sensors [17-22]. Reference [20] mentions that polyaniline is also applied to adsorption processes for the removal of organic pollutants or dyes. There are several reasons why this conducting polymer has recently gained much attention. It's a low cost, simple preparation methods, well-defined electrochemistry, environmental and chemical stability, high conductivity, non-toxic nature, unique redox properties, and tunable properties are a few of them [5, 9-12]. Polyaniline as an adsorbent has limitations like its surface area and crystalline nature of its polymeric chain which can lead to the aggregation of said chains [5,23,24]. It, however, has been determined that when polyaniline is synthesized in the presence of other materials, its properties can be improved.

Natural biopolymer are eco-friendly and non-toxic [25]. The utilization of various types of natural and modified biopolymers for wastewater treatment was reported in literatures [26-29]. Locus bean gum is among the natural biopolymers, which very very rarely exploited for wastewater treatment. Locust bean gum is a galactomannan polysaccharide with a linear chain of $(1 \rightarrow 4)$-linked $\beta$-D-mannopyranosyl units with $(1 \rightarrow 6)$-linked $\alpha$-D-galactopyranosyl residues as side chains [30,31]. According to [32], it was the first galactomannan to be utilized in industries like textiles, paper, cosmetics, as well as food products. It is used as a thickener, stabilizer, or gelling agent in food applications like baked goods, beverages, dairy, and processed fruit [30,33]. Its ability to form a viscous solution at low concentration, stabilize 
dispersion and emulsion, and to replace fat in dairy products are some of the reasons why this polysaccharide is so widely applied [32]. Locust bean gum is natural, biodegradable, non-toxic, and has a relatively low cost. It is a polydisperse, non-ionic molecule, and therefore not affected by ionic strength, $\mathrm{pH}$, or heat processing [32]. Furthermore, it has low solubility in water at ambient temperature and heat treatment is needed for it to reach its maximum solubility and viscosity [1]. Locust bean gum has proven to be a viable adsorbent in the removal of dyes from aqueous solutions whether it was used without modification [7], as a locust bean gum-based hydrogel [1], terpolymer gel composite [34], or a cryogel [33]. It was observed from literature that the adsorption performance of locust bean gum is mainly based on van der Waals forces and hydrogen bonding [7].

To the best of the author's knowledge, a locust bean gum grafted polyaniline composite has not yet been synthesized via in-situ oxidative polymerization and it will also be the first time that this composite will be used for the adsorption of methyl orange from an aqueous solution.

Hence, the present work will include the synthesis of the composite via in-situ oxidative polymerization. In addition, the adsorptive capacity for the removal of methyl orange (MO) was analyzed using a UV-visible spectrophotometer with different dosages of the adsorbent.

\section{EXPERIMENTAL METHOD}

\section{A. Materials}

Aniline (Rochelle Chemicals, 99\%); ammonium peroxydisulfate, APS (Ace, 98\%); hydrochloric acid, $\mathrm{HCl}$ (Ace, $32 \%$ ); dimethyl sulfoxide, DMSO (Merck, $\geq 95 \%$ ); locust bean gum, LBG (Sigma Aldrich); and methyl orange (Ace). All materials were used without any further purification. The chemical formula and structure of methyl orange is provided in Table. 1

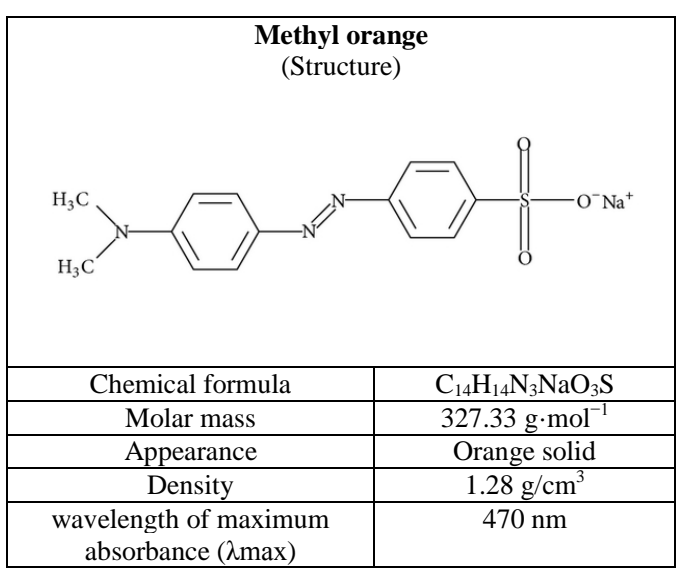

TABLE. I Structure and composition of Methyl orange $(L G P)$

\section{B. Synthesis of Locust Bean Gum Grafted Polyaniline}

Locust bean gum grafted polyaniline (LGP) was synthesized as previously reported by [24], with a few adjustments. $2 \mathrm{~g}$ LBG was dissolved in $75 \mathrm{~mL}$ deionized water. This solution was then heated to $70^{\circ} \mathrm{C}$ to completely dissolve the locust bean gum. The solution was kept at this temperature for 30 minutes under vigorous stirring. After cooling to room temperature, aniline $(20.7 \mathrm{mmol})$ in $1 \mathrm{M} \mathrm{HCl}$ solution was added to the LBG solution under constant stirring. The reaction mixture was stirred for 2 hours while cooling it down to below $5^{\circ} \mathrm{C}$. After 2 hours, $0.6 \mathrm{~g}$ of APS $(2.6 \mathrm{mmol})$ was added to the mixture under vigorous stirring. The reaction mixture was continuously stirred overnight. A large amount of dimethyl sulfoxide (DMSO) was added to the reaction mixture to remove the PANi homopolymer and subsequently centrifuged. The sample was then washed with DMSO until the supernatant was colorless and subsequently dried in an oven at $60^{\circ} \mathrm{C}$ overnight.

\section{Characterization}

The Fourier-transform infrared (FTIR) spectrum of the synthesized adsorbent was obtained using the IRAffinity-1 spectrophotometer of Shimadzu.

\section{Batch Adsorption Experiments}

The adsorption study was carried out using methyl orange (MO) as the model dye in a water solution to investigate the adsorption capacity of the LGP adsorbent. The batch experiments were carried out at $25^{\circ} \mathrm{C}$ in a set of Erlenmeyer flasks to study the effect of the varied adsorbent dosage (20,40, 60 , and $80 \mathrm{mg}$ ). $50 \mathrm{mg}$ of the dye was added to $1 \mathrm{~L}$ of distilled water and the solution $\mathrm{pH}$ was adjusted to seven by adding $\mathrm{HCl}$ $(0.1 \mathrm{~N})$ or $\mathrm{NaOH}(0.1 \mathrm{~N})$. Thereafter, the required amount of adsorbent was added to $50 \mathrm{~mL}$ of the dye solution and was stirred at $160 \mathrm{rpm}$. After 120 minutes, $20 \mathrm{~mL}$ of the samples were collected and centrifuged. The ultraviolet-visible (UV-vis) spectra of the supernatant were analyzed using a GENESYS ${ }^{\mathrm{TM}} 10 \mathrm{~S}$ UV-vis spectrophotometer. The percentage removal of the dye was calculated using (1), where $\mathrm{C}_{0}$ is the initial dye concentration $(\mathrm{mg} / \mathrm{L}), \mathrm{C}_{\mathrm{t}}$ is the dye concentration at time t [35].

$\%$ Removal $=\frac{\left(C_{0}-C_{t}\right)}{C_{0}} \times 100$

The amount of dye adsorbed per unit mass of adsorbent at equilibrium was calculated using (2), where $\mathrm{q}_{\mathrm{t}}$ is the adsorption capacity at time $\mathrm{t}, \mathrm{C}_{0}$ is the initial dye concentration $(\mathrm{mg} / \mathrm{L}), \mathrm{C}_{\mathrm{t}}$ the dye concentration at time $\mathrm{t}, \mathrm{V}$ the volume of the solution $(\mathrm{L})$, and $\mathrm{m}$ the mass of the adsorbent $(\mathrm{g})$.

$$
q_{t}=\frac{\left(C_{0}-C_{t}\right) \times V}{m}
$$

\section{RESULTS AND DISCUSSION}

\section{A. FTIR Characterization}

Fig. 1 illustrates the FTIR spectrum of LGP. The broad band stretching from $3540-3200 \mathrm{~cm}^{-1}$ can be ascribed to the hydrogen-bonded $\mathrm{O}-\mathrm{H}$ stretch. In addition, the peaks at 
$881 \mathrm{~cm}^{-1}$ and $949 \mathrm{~cm}^{-1}$ corresponds with the out of plane hydrogen-bonded O-H. Moreover, the band at $1034 \mathrm{~cm}^{-1}$ can be ascribed to $\mathrm{O}-\mathrm{H}$ bending and the bands between $1154 \mathrm{~cm}^{-1}$ and $1052 \mathrm{~cm}^{-1}$ are due to the $\mathrm{C}-\mathrm{O}$ bond stretching which is characteristic of saccharides. The medium band stretching from $3500-3300 \mathrm{~cm}^{-1}$ is due to the N-H stretching of the amine group; whereas the peaks between $1250 \mathrm{~cm}^{-1}$ and $1020 \mathrm{~cm}^{-1}$ are ascribed to the C-N stretching of the aliphatic amine group. Furthermore, the band at $2927 \mathrm{~cm}^{-1}$ is due to the stretch vibration in reference to $\mathrm{C}-\mathrm{H}$ and $\mathrm{C}-\mathrm{H}_{2}$, more commonly known as $\mathrm{sp}^{3} \mathrm{C}-\mathrm{H}$ stretching. Also, the $\mathrm{C}=\mathrm{O}$ stretching of the carbonyl group is attributed to a band of $1635 \mathrm{~cm}^{-1}$, and the band at $1685 \mathrm{~cm}^{-1}$ can be ascribed to $\mathrm{C}=\mathrm{C}$ stretching. The peak at $1306 \mathrm{~cm}^{-1}$ can be ascribed to the $\mathrm{C}-\mathrm{N}$ and $\mathrm{C}=\mathrm{N}$ stretching which is characteristic of polyaniline. Moreover, the bands at $1553 \mathrm{~cm}^{-1}$ and $1475 \mathrm{~cm}^{-1}$ are the characteristic C-C stretching of the quinoid and benzenoid rings, respectively. These bands are typically found in PANi. Lastly, the band at $811 \mathrm{~cm}^{-1}$ can be attributed to the out of plane bending of C-H.

Taken the above-mentioned into account, it can be concluded that polyaniline was indeed grafted onto locust bean gum.

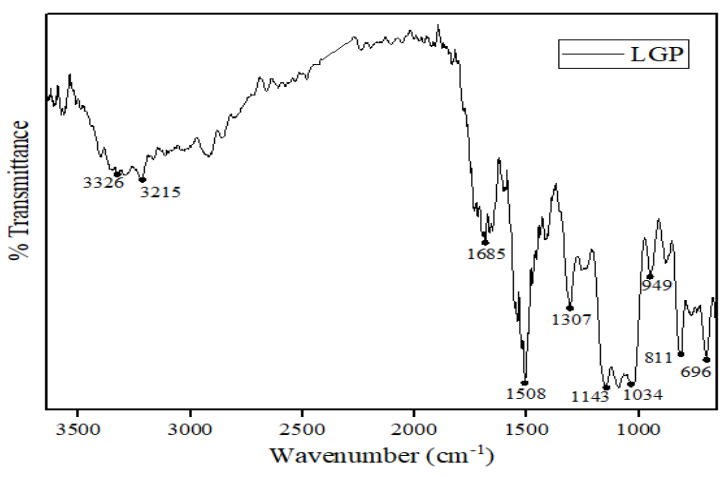

Fig 1: FTIR spectra of LGP

\section{Capacity}

\section{B. Effect of Adsorbent Dosage on the Adsorption}

The adsorbent dosage is an important parameter to consider during the adsorption process as it affects the total amount of active sites available as well as the total specific surface area. This parameter was investigated by varying the adsorbent dosage from $20 \mathrm{mg}$ to $80 \mathrm{mg}(0.4 \mathrm{~g} / \mathrm{L}$ to $1.6 \mathrm{~g} / \mathrm{L})$, with an initial $\mathrm{MO}$ concentration at $50 \mathrm{mg} / \mathrm{L}, \mathrm{pH} 7$, and at a temperature of $25^{\circ} \mathrm{C}$. The contact time was kept constant at 120 minutes. The adsorption capacity increases with the increase in adsorbent dosage (Fig. 2) where a dosage of $1.6 \mathrm{~g} / \mathrm{L}$ showed the best capacity of $20.58 \mathrm{mg} / \mathrm{g}$. Furthermore, the percentage MO removal also increased with an increase of adsorbent dosage (Fig. 3) reaching a maximum of $66 \%$ with an LGP dosage of $1.6 \mathrm{~g} / \mathrm{L}$. Both these increases might be due to the increase in the total number of adsorption sites on the surface as the dose increases. Another reason might be that the total specific area of the surface increases with the increase in dosage.

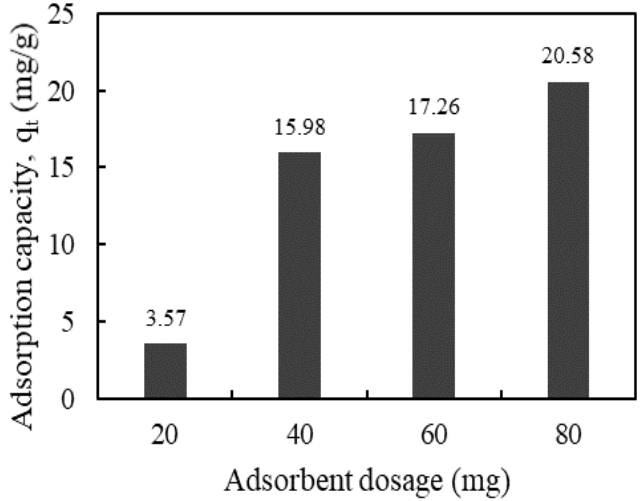

Fig 2: Effect of adsorbent (LGP) dosage on the adsorption capacity (Initial MO concentration: $50 \mathrm{mg} / \mathrm{L} ; \mathrm{pH} 7$; $\mathrm{T}: 25^{\circ} \mathrm{C}$; time: $120 \mathrm{~min}$; V: $50 \mathrm{~mL})$

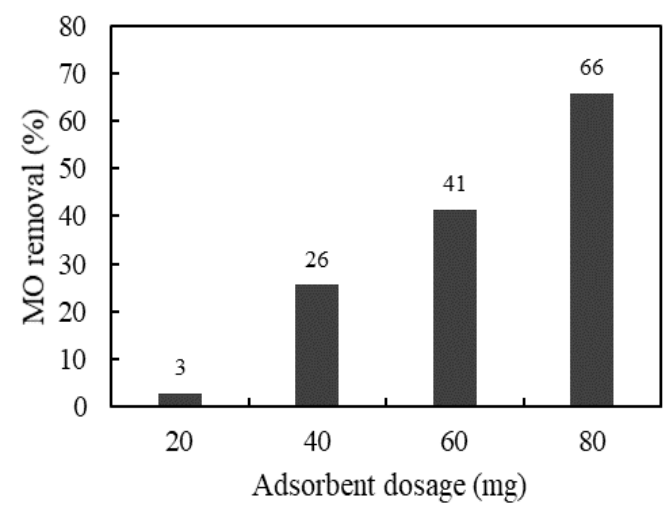

Fig 3: Effect of adsorbent (LGP) dosage on percentage removal of MO (Initial MO concentration: $50 \mathrm{mg} / \mathrm{L} ; \mathrm{pH} 7$; $\mathrm{T}: 25^{\circ} \mathrm{C}$; time: $120 \mathrm{~min}$; V: $50 \mathrm{~mL})$

\section{CONCLUSION}

In this study locust bean gum grafted polyaniline (LGP) via in situ oxidative polymerization has been successfully prepared. FTIR characterizations confirm that graft copolymerization took place. In addition, the LGP dosage showing the best results with regards to adsorption capacity and percentage removal was a dosage of $1.6 \mathrm{~g} / \mathrm{L}$, for both instances. A maximum of $20.58 \mathrm{mg} / \mathrm{g}$ and $66 \%$ was obtained for the adsorption capacity and percentage removal, respectively. Thus, LGP is an effective adsorbent to improve water quality. LGP could replace commercial polymers, with an additional incentive of reduced costs.

\section{ACKNOWLEDGMENT}

The authors are thankful to the sponsor from the North-West University in South Africa.

\section{REFERENCES}

[1] S. Pandey, J.Y. Do, J. Kim, and M. Kang, "Fast and highly efficient removal of dye from aqueous solution using natural locust bean 
gum-based hydrogels as adsorbent," International Journal of Biological Macromolecules, vol. 143, pp. 60-75, Jan. 2020.

https://doi.org/10.1016/j.ijbiomac.2019.12.002

[2] S. Shahabuddin, N.M. Sarih, S. Mohamad, and S.N. Atika Baharin, "Synthesis and characterization of $\mathrm{Co} 3 \mathrm{O} 4$ nanocube-doped polyaniline nanocomposites with enhanced methyl orange adsorption from aqueous solution," Royal Society of Chemistry (RSC) Advances, vol. 6, pp. 43388-43400, Apr. 2016. https://doi.org/10.1039/C6RA04757B

[3] S. Shahabuddin, N.M. Sarih, F.H. Ismail, M.M. Shahid, and N.M. Huang, "Synthesis of chitosan grafted-polyaniline/Co3O4 nanocube nanocomposites and their photocatalytic activity toward methylene blue dye degradation," Royal Society of Chemistry (RSC) Advances, vol. 5, pp. $83857-83867$, Sep. 2015. https://doi.org/10.1039/C5RA11237K

[4] V.K. Gupta, D. Pathania, N.C. Kothiyal, and G. Sharma, "Polyaniline zirconium (IV) silicophosphate nanocomposite for remediation of methylene blue dye from wastewater," Journal of Molecular Liquids, vol. 190, pp. 139-145, Mar. 2009.

https://doi.org/10.1016/j.molliq.2013.10.027

[5] J. Vidya, A.J. Bosco, K. Haribaaskar, and P. Balamurugan, "Polyaniline BiVO4 nanocomposite as an efficient adsorbent for the removal of methyl orange from aqueous solution," Materials Science in Semiconductor Processing, vol. 103, pp. 1-9, July 2019. https://doi.org/10.1016/j.mssp.2019.104645

[6] E.N. Zare, A. Motahari, and M. Sillanpaa, "Nanoadsorbents based on conducting polymer nanocomposites with main focus on polyaniline and its derivatives for removal of heavy metal ions/dyes: A review," Environmental Research, vol. 162, pp. 173-195, Jan. 2018. https://doi.org/10.1016/j.envres.2017.12.025

[7] R.S. Blackburn, "Natural polysaccharides and their interactions with dye molecules: applications in effluent treatment," Environmental Science Technology, vol. 38, pp. 4905-4909, June 2004. https://doi.org/10.1021/es049972n

[8] S. Pandey, J.Y. Do, J. Kim, M. Kang, "Fast and highly efficient catalytic degradation of dyes using $\kappa$-carrageenan stabilized silver nanoparticles nanocatalyst," Carbohydrate polymers vol 230, pp. 115597, 2020 https://doi.org/10.1016/j.carbpol.2019.115597

[9] S. Pandey, S.B Mishra,"Sol-gel derived organic-inorganic hybrid materials: synthesis, characterizations and applications",Journal of sol-gel science and technology vol 59, pp73-94, 2011 https://doi.org/10.1007/s10971-011-2465-0

[10] S. Pandey, S.B Mishra, "Catalytic reduction of p-nitrophenol by using platinum nanoparticles stabilised by guar gum", Carbohydrate polymers vol 113, pp 525-531, 2014 https://doi.org/10.1016/j.carbpol.2014.07.047

[11] S. Pandey, G.K Goswami, H.K Okoro, E. Fosso-Kankeu, "Carbon Nanotubes in the 21st Century: An Advancement in Real Time Monitoring and Control of Environmental Water" in Book: Nano and Bio-Based Technologies for Wastewater Treatment (Chapter.8) 1, pp.265-301, 2019 https://doi.org/10.1002/9781119577119.ch8

[12] E. Fosso-Kankeu, S. Pandey, S.S. Ray, "Photocatalysts in Advanced Oxidation Processes for Wastewater Treatment" John Wiley \& Sons (USA) 1, pp. 320,2020 https://doi.org/10.1002/9781119631422

[13] S. Pandey, KK Mandari, J Kim, M Kang, E Fosso-Kankeu, "Recent Advancement in Visible-Light-Responsive Photocatalysts in Heterogeneous Photocatalytic Water Treatment Technology", Photocatalysts in Advanced Oxidation Processes for Wastewater Treatment, pp. 167-196, 2020 https://doi.org/10.1002/9781119631422.ch6

[14] S.M Sayyah, A.A. Essawy, and A.M. El-Nggar, "Kinetic studies and grafting mechanism for methyl aniline derivatives onto chitosan: Highly adsorptive copolymers for dye removal from aqueous solutions," Reactive and Functional Polymers, vol. 96, pp. 50-60, Sep. 2015. https://doi.org/10.1016/j.reactfunctpolym.2015.07.005

[15] S. Pandey, "A comprehensive review on recent developments in bentonite based materials used as adsorbents for wastewater treatment", Journal of Molecular Liquids vol 241, pp. 1091-1113, 2017 https://doi.org/10.1016/j.molliq.2017.06.115

[16] S. Pandey, J. Ramontja, "Natural Bentonite Clay and Its Composites for Dye Removal: Current State and Future Potential", American Journal of Chemistry and Applications vol 3(2), pp. 8-19,2016
[17] S. Sedaghat, and F. Golbaz, "In situ oxidative polymerization of aniline in the presence of manganese dioxide and preparation of polyaniline/MnO2 nanocomposite," Journal of Nanostructure in Chemistry, vol. 3, pp. 1-3, Aug. 2013.

https://doi.org/10.1186/2193-8865-3-65

[18] Khan, "Statistical applications for photocatalytic dye degradation and sorption models study assess by $\mathrm{Co} 3 \mathrm{O} 4$ nanoadsorbent," Materials Today Chemistry, vol. 17, pp. 1-14, Jun. 2020. https://doi.org/10.1016/j.mtchem.2020.100330

[19] Y. Wu, J. Wang, B. Ou, S. Zhao, and Z. Wang, "Some important issues of the commercial production of 1-D nano-PANI," Polymers, vol. 11, pp. 1-24, Apr. 2019. https://doi.org/10.3390/polym11040681

[20] M. Ayad, and S. Zaghol, "Nanostructured crosslinked polyaniline with high surface area: synthesis, characterization and adsorption for organic dye," Chemical Engineering Journal, vol. 204-206, pp. 79-86, July 2012. https://doi.org/10.1016/j.cej.2012.07.102

[21] S. Pandey, J. Ramontja, "Rapid, facile microwave-assisted synthesis of xanthan gum grafted polyaniline for chemical sensor", International Journal of Biological Macromolecules vol 89, pp 89-98,2016 https://doi.org/10.1016/j.ijbiomac.2016.04.055

[22] S. Pandey, "Highly Sensitive and Selective Chemiresistor Gas/Vapor Sensors based on Polyaniline Nanocomposite: A comprehensive review" Journal of Science: Advanced Materials and Devices vol 1, pp 431-453, 2016 https://doi.org/10.1016/j.jsamd.2016.10.005

[23] M.M. Ayad, A.A. El-Nasr, and J. Stejskal, "Kinetics and isotherm studies of methylene blue adsorption onto polyaniline nanotubes base/silica composite," Journal of Industrial and Engineering Chemistry, vol. 18, pp. 1964-1969, May 2012. https://doi.org/10.1016/j.jiec.2012.05.012

[24] M. Abbasian, M. Jaymand, P. Niroomand, A. Farnoudian-Habibi, and S.G. Karaj-Abad, "Grafting of aniline derivatives onto chitosan and their applications for removal of reactive dyes from industrial effluents," International Journal of Biological Macromolecules, vol. 95, pp. 393-403, Nov. 2016. https://doi.org/10.1016/j.ijbiomac.2016.11.075

[25] S. Pandey, C.D Klerk, J. Kim, M. Kang, E. Fosso-Kankeu, "Eco Friendly Approach for Synthesis, Characterization and Biological Activities of Milk Protein Stabilized Silver Nanoparticles", Polymers vol 12 (6), pp 1418, 2020 https://doi.org/10.3390/polym12061418

[26] L.P Simelane, E. Fosso-Kankeu, P. Njobeh, S. Pandey, "Response of bacterial biosorbents to chemical treatment as influenced by cell membrane structure and impact on the adsorption behaviour of dyes" Current Science vol 114 (4), pp 826-834,2018 https://doi.org/10.18520/cs/v114/i04/826-834

[27] C. Mampho, S. Pandey, J. Ramontja, E. Fosso-Kankeu, F. Waanders, "Synthesis and Characterization of Superabsorbent Hydrogels Based on Natural Polymers: Kappa Carrageenan" Int'l Conf. on Advances in Science, Engineering, Technology \& Natural Resources (ICASETNR-16) pp. 64-67, 2016

[28] S. Pandey, E. Fosso-Kankeu, J. Ramontja, Efficient and rapid adsorption characteristics of templating xanthan gum-graft-poly (aniline) and silica nanocomposite toward removal of toxic methylene blue dyes, 9th Int'l Conference on Advances in Science, Engineering, Technology \& Waste Management, pp. 136-141, 2017

[29] E. Fosso-Kankeu, M. Van den Berg, S. Pandey, F.Waanders, Removal of COD from Biodiesel Wastewater using a Hydrophobic Polymer", 10th International Conference on Advances in Science, Engineering, Technology and Healthcare (ASETH-18), pp. 159-163, 2018

[30] S. Barak, and D. Mudgil, "Locust bean gum: processing, properties and food applications - a review," International Journal of Biological Macromolecules, vol. 66, pp. 74-80, Feb. 2014 https://doi.org/10.1016/j.ijbiomac.2014.02.017

[31] R.I. Mahmoud, "Preparation and characterization of polyacrylic acid-locust bean gum," Journal of Reinforced Plastics and Composites, vol. 28, pp. 2413-2427, July 2008. https://doi.org/10.1177/0731684408092368

[32] P.A. Dakia, C. Blecker, C. Robert, B. Wathelet, and M. Paquot, "Composition and physicochemical properties of locust bean gum extracted from whole seeds by acid or water dehulling pre-treatment," Food Hydrocolloids, vol. 22, pp. 807-818, Mar. 2007 https://doi.org/10.1016/j.foodhyd.2007.03.007 
[33] X. Hu, L. Yan, Y. Wang, and M. Xu, "Freeze-thaw as a route to build manageable polysaccharide cryogel for deep cleaning of crystal violet," Chemical Engineering Journal, vol. 396, pp. 1-10, May 2020. https://doi.org/10.1016/j.cej.2020.125354

[34] A.A. Zauro, V. Badalamoole, "Synthesis of locust bean gum-based terpolymer bentonite composite: evaluation for indigo carmine adsorption," International Journal of Advanced Chemistry, vol. 5, pp. 61-69, Aug. 2017. https://doi.org/10.14419/ijac.v5i2.7930

[35] M. Hasan, M. Rashid, M.M. Hossain, M.K. Al Mesfer, M. Arshad et al., "Fabrication of polyaniline/activated carbon composite and its testing for methyl orange removal: optimization, equilibrium, isotherm and kinetic study," Polymer Testing, vol. 77, pp. 1-9, May 2019. https://doi.org/10.1016/j.polymertesting.2019.105909 